\title{
Arbor
}

\section{Corazón: Ciencia y Literatura}

\author{
Ángel Martín Municio
}

Arbor CLXXIX, 706 (Octubre 2004), 473-493 pp.

Hay en la historia de la civilización unos cuantos temas centrales que han afectado a la vez a la consideración del universo, del hombre y de sus actividades. Y, por igual, nombres que en esta historia supieron introducir nuevas ideas sobre el funcionamiento, también, del universo y del hombre.

Ha sucedido, pues, que, durante muchos siglos, no se supiera a ciencia cierta ni la naturaleza del universo, ni el centro del cosmos. Y, por igual, durante muchos siglos, se ha ignorado cual era la organización del cuerpo humano y cuales de sus partes eran responsables de su funcionamiento general y de sus disposiciones particulares.

$\mathrm{Si}$, en la solución de estos planteamientos, hubo una aproximación cuya figura central fue Galileo (1564-1642), quien publicó en $1632 \mathrm{el}$ "Diálogo sobre los dos sistemas máximos del mundo", y mediante la cual se confirmó la tesis heliocéntrica, en la que la Tierra quedaba en cierta manera degradada a la simple posición de un planeta, más o menos importante, del sistema solar. Curiosamente, por las mismas fechas, en 1628, Harvey estableció la circulación de la sangre. Y, se ha parangonado, que lo que el Sol era en el macrocosmos respecto de la Tierra, eso mismo sería el corazón en el microcosmos animal y humano respecto de las partes periféricas. Abundando en ello, Harvey, en su obra fundamental, De motu cordis, aseguraría: "Todas las partes del cuerpo se nutren, se calientan y crecen con la sangre más cálida, perfecta, vaporosa, espirituosa $y$, por así decirlo, alimentativa; $y$, por el contrario, en las partes la sangre se enfría, se coagula y se agota; por lo cual vuelve al principio, esto es, al corazón, como al manantial o al hogar del cuerpo, para recuperar su perfección: como un tesoro de vida, recobra su fluidez, impregnándose de espíritus $y$, por así decirlo, de bálsamo; desde alli se dis- 
tribuye de nuevo, y todo esto depende del movimiento y el pulso del corazón".

No deja de ser bonito, además, que las tradiciones de ambas ideas, durante siglos, tuvieran simbolismos comunes tanto en el ensalzamiento antropocéntrico de la cosmología, como en el del corazón del hombre en el seno de su biología. La tradición, pues, durante siglos, desde la literatura testamentaria hasta nuestros mismos días, ha hecho del corazón una víscera que fuera tenida como la sede de las cualidades del alma, y el símbolo del sentido moral, de las virtudes y de las pasiones. Quizá no pueda venir más a cuento a este propósito que el conocido texto de Ezequiel (36,26): "Os daré un corazón nuevo y os infundiré un espíritu nuevo; arrancaré de vosotros el corazón de piedra y os daré un corazón de carne». Porque desde los profetas y los apóstoles hasta hoy resulta válida la metáfora de mover el corazón como caminar hacia el bien. Víscera noble también como para llegar a ser recogida tras la muerte de los héroes, embalsamada y ofrecida a la veneración popular; tal como se referiría Cervantes, en el Quijote, cuando asegura: "Lo que a mi me admira es, que sé tan cierto como ahora es de día, que Durandarte acabó los de su vida en mis brazos, y que después de muerto le saqué el corazón con mis propias manos".

A la vez, sin embargo, una víscera que, en nuestra misma época, ha liderado los objetivos de los fabulosos avances tecnológicos recientes; entre otros, los transplantes que hicieron famosa la fecha del 19 de diciembre de 1967 en la que el doctor Barnard realizó en la ciudad de El Cabo el primer transplante cardiaco; las técnicas quirúrgicas al estilo del cateterismo cardiaco y la angiografía, que permiten precisar con exactitud la localización, el carácter, la dimensión y la dinámica de cada una de sus anomalías; la cirugía a corazón abierto -cuyas primeras operaciones datan de 1953- asistida por la circulación extracorpórea, gracias al sistema de corazón-pulmón artificial cuyo primer dispositivo fue empleado en 1955; y los estimuladores implantables. Sin olvidar las técnicas no invasivas de diagnóstico cardiovascular, al estilo de las múltiples variantes de la electrocardiografía, la ecocardiografía, y la resonancia magnética, y, por supuesto, la moderna terapéutica farmacológica, centrada en los agentes -bloqueantes con su participación en el control de la hipertensión, y en los agentes fibrinolíticos supresores de trombos.

Es del todo seguro que el corazón ha alcanzado todos estos tratamientos, con su extraordinario interés, debido a su autonomía funcional, consecuencia de sus propiedades especificas y motivo tanto del automa- 
tismo que permite mantener la vida vegetativa del hombre cuando reposa o cuando duerme, como de la adaptación del ritmo y de la fuerza de sus contracciones a las numerosas variantes de las condiciones fisiológicas del esfuerzo. Si, además, en esta adaptación juega un papel esencial el sistema nervioso, tanto en el gobierno del músculo cardiaco mismo como en el de la cesión sanguínea a la periferia del organismo; no tendrá nada de extraño la importante y creciente colección de hechos de su fisiopatología, sobre todo -como veremos en seguida- el extraordinario crecimiento de las cardiopatías que dan cuenta de más de un tercio de la mortalidad humana, como dificultad de adaptación al esfuerzo físico, al ambiente de un mundo agresivo, y a las modificaciones de los hábitos y comportamientos alimentarios. A lo que añadir, de paso, que la mejor descripción de las anomalías congénitas humanas de la estructura del corazón es a modo de símbolo de su propia embriogénesis y recuerdo evolutivo del corazón animal; sin olvidar los progresos en el examen clínico y radiológico, las investigaciones manométricas y las nuevas técnicas quirúrgicas.

¿Tendrá, entonces, algo de extraño que, desde la ciencia griega hasta la sofisticada descripción moderna de su formidable conocimiento anatómico y fisiopatológico, el simbolismo del corazón haya sido, a la vez, motivo permanente de inspiración poética y literaria, en general, e, incluso, justifique las mismísimas creaciones populares de la lengua?

Antes de nada, convendrá decir que, en el seno de la anatomía animal, el término corazón designa los sacos contráctiles situados en el trayecto de los vasos del aparato circulatorio. Sin embargo, la denominación se reserva para un saco contráctil único implicado en esquemas complejos de diferenciación. Por ejemplo, en los Crustáceos, situado en el retículo dorsal; en los Moluscos, que comporta dos elementos contráctiles en serie, una pequeña aurícula y un ventrículo; en los Vertebrados, el corazón más simple es el de los peces que alinea cuatro cavidades: seno venoso, aurícula primitiva, ventrículo y bulbo arterial. Una disposición semejante se encuentra en los embriones de los Vertebrados aéreos; $y$, conforme a ello, el embrión humano, en el día 22, presenta un corazón comparable al de los peces. Y, en el transcurso del desarrollo, este corazón embrionario experimenta una tabicación longitudinal, que permanece incompleta en los Batracios y los Reptiles, y resulta completa en las Aves y Mamíferos. A este estado avanzado de evolución, la ausencia de comunicación entre las mitades derecha e izquierda del corazón que caracteriza a los Vertebrados superiores significa un importante progreso porque va a separar rigurosamente la circulación pulmonar y la circulación general. 
El corazón fue definido, hace casi tres siglos, por el famoso «Diccionario de Autoridades», de la Real Academia Española, como «la parte más noble y principal del cuerpo humano y de los animales: el cual es un pedazo de carne dura, que termina en punta, y está situado en medio del pecho. Es el primero que se forma y anima, y el postrero que muere, y es como un centro, principio y fin de todo movimientor.

El corazón humano, lo definiríamos hoy como una víscera hueca, de unos $260 \mathrm{~g}$, situada en la cavidad torácica, entre los pulmones, en la encrucijada de las grandes arterias y las grandes venas del organismo. Se trata de un órgano contráctil que engendra la circulación sanguínea y juega un papel esencial en la regulación de esta función y en su adaptación a las variaciones fisiológicas, en particular del esfuerzo.

Desde hace tiempo se conoce que el corazón humano tiene cuatro cavidades, separadas en dos mitades independientes, aisladas por un tabique longitudinal que lo divide en una parte izquierda y otra derecha e impide la mezcla de la sangre oxigenada y la sangre desoxigenada. Cada una de estas mitades se compone de una auricula que almacena la sangre, y de un ventrículo que, debido a su contracción -la sístole- lanza la sangre hacia el exterior. Cada uno de estos pares de cavidades, compuesto de aurícula y ventrículo, contacta por medio de las válvulas correspondientes: la válvula aurículo-ventricular izquierda es la mitral y la válvula aurículo-ventricular derecha es la tricúspide. La mitad izquierda -concretamente la aurícula izquierda- recibe la sangre, oxigenada en los pulmones, a través de las 4 venas pulmonares; y, desde esta cavidad, la sangre pasa al ventrículo izquierdo para ser distribuida a todos los órganos por medio de la arteria aorta. La mitad derecha recupera primero la sangre venosa, privada de oxígeno, a través de las venas cavas y la propulsa después a los pulmones a través de la arteria pulmonar para ser oxigenada nuevamente. En los vasos de salida, tanto en la arteria aorta como en la arteria pulmonar, existen asimismo unas válvulas -las válvulas sigmoideas- que impiden el reflujo de la sangre hacia el corazón.

Es evidente que, aunque resumida ahora, a esta gran complicación estructural del corazón humano adulto se ha llegado a través de una colección de etapas evolutivas, que se van a ver reflejadas en la armonía de su propia embriogénesis. Complejidad estructural que se corresponde con la finura y multiplicidad de las funciones fisiológicas que el corazón debe cumplir. Pero que, también, por otro lado, ofrece una enorme colección de sedes para la localización de las numerosas disfunciones patológicas, tanto congénitas como adquiridas. 


\section{Corazón: Ciencia y Literatura}

A este conocimiento actual se ha llegado a través de unas cuantas largas etapas de la historia. Ya Platón, en el Timeo, coincidía con todas las doctrinas de Filistión de Locros, principal representante del saber médico en Siracusa en el siglo IV aC, que llevó a cabo disecciones humanas en las que no tuvo otros antecedentes que Alcmeón de Crotona dos siglos antes. Platón coincidía con el uasentamiento en el corazón del calor innato»; con que "la función de la respiración era atemperar dicho calor»; y con la vieja creencia helénica que describía el poeta Alceo en el verso "humedece los pulmones con vino", relativa al paso de la bebida por los pulmones. Filistión, sin embargo, al igual que toda la escuela siciliana, asentaba la inteligencia en el corazón. Y frente a ello, Alcmeón la había alojado en el cerebro; y Platón creía en un alma tripartita: el alma inferior o concupiscible reside en el vientre, debajo del diafragma; el alma afectiva mora en el corazón, y la inteligencia habita en el cerebro.

Media docena de siglos después, Galeno, griego de nacimiento aunque vivió en Roma en el siglo II después de Cristo, devoto de Esculapio, y médico del Emperador romano Severo, considerado como el Príncipe de los Médicos después de Hipócrates, había constatado ya la existencia de un doble sistema, el corazón y la sangre, haciendo uso tan sólo de la disección de animales inferiores. Galeno, siguiendo a los grandes anatomistas alejandrinos Herophilo y Erasístrato -creadores de la escuela empírica, que habían dirigido la medicina hacia un camino rigurosamente científicohabía colocado las venas en la parte derecha del cuerpo, y las arterias en la izquierda. Las venas se originarían en el hígado, y la sangre venosa, a modo de alimento, habría de nutrir ambas partes del organismo; en tanto que las arterias, originadas en el corazón, suministrarían una especie de contenido vital. Para Galeno, la sangre venosa era una consecuencia de los alimentos que ingerimos; los que en el estómago se transformarían en el quilo, fluido lechoso, luego transportado al hígado, de forma que cada parte del organismo tendría el poder de atraerlo y cambiarlo en su propia sustancia. De esta manera, el hígado -con un aspecto de sangre congela$d a$, decía Galeno- transformaba el quilo en su propia sustancia sanguínea. La sangre arterial, al contrario, se cargaría en los pulmones con una especie de aire espirituoso o pneuma e iría luego a parar a la cavidad izquierda del corazón. Allí se mezclaría con la sangre venosa procedente de la cavidad derecha; y, de esta manera, la sangre venosa, espesa, oscura, cargada de materiales de desecho, se haría más fluida y brillante, para regresar a los pulmones a través de la vena pulmonar.

¿Cómo, sin embargo, se movía la sangre; cómo la sangre venosa alcanzaba la cavidad izquierda del corazón? La noción de circulación, es 


\section{Ángel Martín Municio}

decir el movimiento de la misma sangre en forma de círculo, le fue completamente ajena a Galeno. Para Galeno, era la necesidad de nutrición de las diversas partes del cuerpo la que originaba una atracción de la sangre venosa hacia ellas, sin que tuviera lugar movimiento regular alguno de ningún tipo. Y, por otro lado, consideraba que la diástole-la aspiración de la sangre- era el único movimiento del corazón, y que las arterias poseían una actividad pulsátil con que contribuir al movimiento de la sangre. Para solucionar el problema de cómo la sangre venosa movería desde la parte derecha hacia la izquierda del corazón, Galeno sugirió que la pared separadora -el septum- estaría dotada de unos poros invisibles. Además, la insistencia con que contemplaba la separación lateral de venas -en la parte izquierda-y arterias -en la parte derecha-, dificultó la aceptación de que la arteria pulmonar -situada en la izquierda- era una arteria tanto en estructura como en función; tan difícil que Galeno la denominó vena arterial.

En resumen, el sistema de Galeno fue capaz de interpretar algunos fenómenos importantes, de acuerdo con la época, tales como la nutrición, el crecimiento, las sensaciones, etc. Sistema galénico cuya importancia queda subrayada sólo con pensar cómo permaneció en vigor y atravesó la época griega, árabe, medieval y alcanzó el Renacimiento. La debilidad, sin embargo, del sistema de Galeno consistía principal y lógicamente en defectos de observación: la acción del corazón exclusivamente en diásto$l e$, el origen de las venas en el hígado, la existencia de poros en el septo intercavitario y el rechazo del tránsito pulmonar de la sangre. Situación que, tras muchos siglos, pudo ser contradicha por la observación directa humana de los anatomistas del Renacimiento en el siglo XVI, cuyo liderazgo fue ejercido por Andreas Vesalio, médico del Emperador Carlos V, a través sobre todo de su monumental obra De Humani Corporis Fabrica, editada en 1543.

Diez años más tarde, en 1553, Miguel Servet fue quemado en la Ginebra calvinista con todas las copias que se encontraron de su obra herética Christianismi Restitutio, publicada el mismo año. Un anticuario inglés publicó, sin embargo, en 1694, la obra de Servet. En ella, y a propósito de la expresión bíblica, cuando el Génesis (9.4) dice "Solamente os abstendréis de comer carne con su alma, es decir, su sangrel, se preguntaba Servet cómo el espíritu divino entraba en el hombre y, basada en sus trabajos en París con Guinther von Andermacht -el maestro de Vesalio-, su explicación era que a causa del tránsito pulmonar de la sangre. La interpretación literal de la Biblia era, sin embargo, que «la sangre era 


\section{Corazón: Ciencia y Literatura}

el asiento del alma y que el alma era expirada en el hombre por Dios"; a lo que Servet argüía que son los pulmones los que, precisamente, suministran el lugar de contacto entre la sangre y el aire -el alma bíblica-, con lo que se originaría la sangre arterial.

Fue ya en pleno siglo XVII cuando William Harvey, médico en el hospital de San Bartolomé de Londres y médico de los Reyes ingleses Jaime I y Carlos I, pudo confirmar tanto el tránsito pulmonar de la sangre como la actuación del corazón a modo de músculo con una doble capacidad, de diástole como aspiración y de sistole como expulsión de la sangre. En 1628, Harvey publicó Exercitatio Anatomica de Motu Cordis et Sanguinis in Animalibus en el que anunció el descubrimiento de la circulación de la sangre. En su capítulo 8, Harvey describe una gran cantidad de estructuras anatómicas de vasos y válvulas, y el tamaño de las arterias conectadas al corazón. Con ello y con una colección de sencillos experimentos de ligazón entre vasos, Harvey pudo concluir que la sangre se movía en un círculo -había, por tanto una circulación- y que la presencia de una serie de válvulas en las venas sirve para dirigir siempre la sangre hacia el corazón, y en ningún caso para impedir la inundación sanguínea de las extremidades del organismo. $\mathrm{Y}$ en la dedicatoria de este libro al Rey Carlos I, Harvey, en su armoniosa visión del mundo, con el Sol, el Rey y el corazón como los centros visibles de la realidad, proclamaba: "El corazón de los animales es el fundamento de la vida, el principio de todas las cosas, el Sol del microcosmos; de él depende todo crecimiento y emana todo vigor y toda fuerza. De la misma manera, el Rey, fundamento de su reino y Sol de su microcosmos, es el corazón de la república y de él emana toda potestad y procede toda gracia...Y así como todo lo humano tiene como modelo ejemplar al hombre, el Rey se conforma en gran parte al modelo del corazón".

Del escrito De motu cordis iba a salir toda una colección de insospechadas consecuencias sobre la diferencia entre la sangre venosa y la sangre arterial, es decir de la función pulmonar; lo que iba a conducir al esclarecimiento de la relación entre la circulación menor y los procesos respiratorios, del paso de la sangre desde las arterias a las venas y de la contracción de las fibras cardiacas.

Una vez completado este conocimiento anatómico a través de la historia, y, merced a las recientes aportaciones de la ciencia y la tecnología, se ha llegado a la espléndida situación con que hoy puede interrogarse el funcionamiento del corazón, comenzando por la irremplazable auscultación que sirve para el análisis fino de los sonidos cardiacos, normales o 
anormales; para la detección de los soplos patológicos que constituyen los índices más precoces, sensibles y fieles, de las alteraciones de las válvulas; y para la recogida de información sobre la existencia de comunicaciones intracardiacas anormales, y sobre el estado del miocardio o del pericardio. Y siguiendo por los exámenes radiológicos, reveladores de su posición en el tórax, las modificaciones de forma y de dimensión de los contornos del corazón, y las alteraciones de sus latidos; los exámenes electrocardiográficos, registradores de las variaciones de potencial inducido en la superficie de la piel por la actividad de las fibras del miocardio, de las que pueden deducirse, entre otras condiciones, el estado de la conducción intracardiaca, la hipertrofia de las paredes del corazón, y la existencia de isquemias miocárdicas o de alteraciones metabólicas; las técnicas de cateterismo que permiten guiar una sonda, opaca a los rayos $\mathrm{X}$, a las cavidades derecha -a través de una vena del brazo-o izquierda -ordinariamente, a través de la arteria femoral-y han permitido en el último cuarto de siglo la identificación y tratamiento de las complejas cardiopatías congénitas o valvulares, de la morfología de los grandes troncos coronarios, y la sede y la forma de las oclusiones y los estrechamientos patológicos; y las numerosas pruebas bioquímicas que valoran los distintos parámetros lipídicos -lípidos, lipoproteínas y colesterol-, glucosa y ácido úrico, anticuerpos antiestreptocócicos, y, mas recientemente, la presencia de enzimas liberadas en la necrosis de las fibras miocárdicas.

A través de estas pruebas se identifican hoy las cardiopatías o enfermedades del corazón, que, hasta época reciente, no han tenido importancia cuantitativa desde un punto de vista epidemiológico. Sin embargo, las transformaciones radicales de las condiciones de vida, debido al desarrollo de las técnicas agrícolas e industriales, y al eficaz control de la mayoría de las enfermedades infecciosas, han modificado esta situación en el último medio siglo. Hasta el punto de que, por su frecuencia y gravedad, son hoy las enfermedades del corazón y de los vasos las de más importancia en la epidemiología humana, ya que alcanzan entre el 30-50\% de la mortalidad en los países desarrollados. Datos que no sólo representan el doble de la mortalidad debida al cáncer y a las enfermedades infecciosas, sino que no cesa de crecer, durante el último cuarto de siglo, en la mayor parte de los países del mundo, principalmente en Europa donde la prevalencia de las enfermedades cardiacas constituye la contrapartida inevitable del aumento de la calidad de vida. Y, de aquí, el interés creciente, durante los últimos años, en la identificación y tratamiento de las cardiopatías, acompañado de una intensa investigación científica y tecnológica. 


\section{Corazón: Ciencia y Literatura}

En cualquier caso, las enfermedades del sistema vascular resultan de una mezcla compleja de factores de susceptibilidad genética y ambiental. Y las tecnologías y las estrategias que emanan del conocimiento del genoma humano han sido aplicadas al análisis tanto de las muy raras enfermedades monogénicas, como de las muy comunes enfermedades vasculares multigénicas, con el fin de identificar nuevos genes y nuevos mecanismos propios de los trastornos cardiovasculares.

El defecto más extendido del ritmo cardiaco y el más conocido por el público es la fibrilación auricular que consiste en la sucesión extraordinariamente rápida e irregular de los estímulos eléctricos con la pérdida de sincronización de las contracciones de las fibras cardiacas de las aurículas. Puede llegar a afectar al 1\% de la población total y al 5\% de los individuos de más de 65 años; y, debido al progresivo envejecimiento de la población en los países desarrollados, esta frecuencia se duplica en cada decenio. Se manifiesta, más o menos ocasional o permanentemente, por palpitaciones, lipotimias y síncopes, pudiendo provocar una insuficiencia cardiaca aguda, un edema pulmonar o una embolia.

Sin entrar en excesivos detalles, merece la pena resaltar el interés de las malformaciones congénitas del corazón y de los grandes vasos, en su relación -como ya ha quedado mencionado- con la detención o las anomalías del conjunto perfectamente orquestado de sucesos morfogenéticos y moleculares que constituyen el desarrollo embrionario. Las anomalías cromosómicas no son formas familiares frecuentes de las cardiopatías congénitas. Las infecciones virales, como la rubeola, contraídas durante los dos o tres primeros meses de embarazo, aunque raras, son causa de este tipo de cardiopatías congénitas, aunque -conviene distinguir- no hereditarias. Sin embargo, muchas de estas anomalías, en un tiempo atribuidas a etiologías multifactoriales, van considerándose debidas a mutaciones en los genes controladores del desarrollo. Así, por ejemplo, se han descrito mutaciones cromosómicas responsables de las anomalías septales de las auriculas -5q34-, anomalías septales de los ventrículos -12q24-, tetralogía de Fallot-20p12-, aneurisma aórtico-15q21-, y de la estenosis aórtica supravalvular-7q11-.

La mayor parte de las cardiopatías congénitas comportan -como su mismo nombre indica- una o varias comunicaciones anormales entre las dos partes, derecha e izquierda, del corazón, o los dos grandes vasos arteriales que de él emergen, con lo que se origina toda una serie de comunicaciones interauriculares, interventriculares o aortapulmonares; las cuales representan más de la mitad de las enfermedades congénitas del 
corazón. Estas anomalías congénitas de la comunicación favorecen un tránsito asimismo anómalo, con una serie de consecuencias clínicas, que imponen la intervención quirúrgica para restablecer la comunicación anatómica normal. En la enfermedad azul o tetralogía de Fallot, coexiste una comunicación interventricular que coloca la aorta sobre los dos ventrículos y un estrechamiento del infundíbulo del ventrículo derecho con la hipertrofia de esta cavidad.

Existe otra serie de cardiopatías congénitas que no implican comunicaciones anormales intracardiacas como las descritas anteriormente. Se suele tratar casi siempre de estrechamientos más o menos pronunciados o de la malformación de los orificios valvulares, como la enfermedad de Ebstein en la que se encuentra afectada la válvula tricúspide, o en los estrechamientos aórticos congénitos. Situaciones que se corrigen hoy perfectamente, gracias a la circulación extracorpórea que permite la apertura del corazón y el examen y corrección cuidadosa de las alteraciones estructurales cardiacas.

Al lado de las cardiopatías congénitas, las de naturaleza adquirida se centran principalmente en el reumatismo cardiaco articular agudo, más frecuente en los niños, y ocasionado por una infección por estreptococos hemolíticos. Ataca las diversas túnicas que comportan los tejidos del corazón, sobre todo el miocardio, y a menos de un tratamiento antimicrobiano y antiinflamatorio suficientemente intenso y precoz, corre el grave riesgo de una lenta evolución con deformaciones valvulares progresivas, con afectación de una o de varias válvulas -preferentemente la mitral, la aórtica o la tricúspide- y las consiguientes consecuencias clínicas. Las más frecuentes enfermedades cardiovasculares en la edad adulta son las cardiopatías isquémicas, principalmente debidas a aterosclerosis coronarias, que afectan $4-5$ veces más al hombre que a la mujer -por ahora-, y cuyos factores de riesgo son el tabaquismo, la obesidad, la hipertensión, el sedentarismo y la hipercolesteremia. La característica fundamental es la formación patológica de la placa de ateroma en las paredes coronarias, a base de depósitos lipídicos, sales de calcio y fibras; y como consecuencia del estrechamiento, la reducción del flujo sanguíneo en las arterias coronarias y, por tanto, del aporte de oxígeno al músculo cardiaco, y, debido a ello, la anoxia más o menos severa y pronunciada del miocardio. Esta insuficiencia coronaria, cuando es intensa y durable, produce la isquemia de las fibras cardiacas y una lesión definitiva, más o menos masiva y más o menos extensa, del músculo, lo que constituye el sustrato anatómico del infarto de miocardio. Recientemente, la imagen de resonancia magnética (MRI) permite eva- 
luar los daños anatómicos y fisiológicos producidos en el miocardio isquémico.

Finalmente, existen numerosas causas de agresión externa -bacterianas, virales, parasitarias, tumorales, etc.- que dan lugar a variadas manifestaciones inflamatorias, agudas o crónicas, del pericardio. En algunos casos, la invasión de patógenos viene motivada por la deficiencia de los mecanismos de tolerancia inmunitaria; y en ciertos casos, la reacción autoinmune es causa de cardiomiopatías de etiología desconocida.

Antes de dejar, sin embargo, esta visión del corazón desde el punto de vista de la ciencia y de la técnica, es importante dejar constancia de cómo las alteraciones cardiovasculares han sido objeto recientemente de la moderna terapia génica. En efecto, en 1997, en la reunión de la Asociación Americana de Cardiología se presentó el primer caso de empleo de la terapia génica para promover el crecimiento de nuevos vasos sanguíneos. Esta terapia ha supuesto la inyección de un gen promotor del crecimiento de nuevas arterias -VEGF, factor de crecimiento vascular endotelial, estimulador de la angiogénesis- en las piernas de pacientes con grave afectación; y de los 20 pacientes tratados, en 16 se crearon nuevos vasos funcionales, con la curación o mejora de las lesiones ulcerosas y gangrenas ocasionadas por una circulación sanguínea deficiente. La posibilidad de recrear el músculo cardiaco a partir de células madre -de origen embrionario terapéutico o de otra procedencia alternativa- tiene abierta hoy una impresionante posibilidad de lucha contra la insuficiencia cardiaca.

La investigación prosigue en el sentido de administrar los genes directamente en el corazón, con lo que podría obviarse un buen número de intervenciones quirúrgicas. En efecto, actualmente las intervenciones cardiacas alargan cada año la vida de 300000 personas en todo el mundo; y algunos expertos aseguran que los avances científicos -genes, láseres- tenderán a hacer desaparecer este tipo de cirugía. A su lado, el trasplante de corazón, la única solución para muchos pacientes, salva cada año la vida a 3000 pacientes en todo el mundo, aunque muchísimos más esperan la compatibilidad de una donación. A resolver esta situación puede contribuir la preparación de cerdos transgénicos, que no reconozcan los antígenos humanos y, así, se logre evitar el por otro lado inevitable rechazo de nuestros días. Rechazo que, evidentemente, también se evita con un corazón artificial, de alrededor de $1 \mathrm{~kg}$ de peso, puesto a la venta en Estados Unidos, hace pocos meses, al precio de $\$ 75000$. 
Finalmente, merece mencionarse un amplio estudio epidemiológico llevado a cabo en Finlandia, durante diez años, con 4630 recién nacidos a los que se ha controlado su desarrollo -18 medidas de peso y altura hasta los 12 años- y la presencia de alteraciones cardiovasculares hasta la edad adulta. Un pobre desarrollo durante el primer año de vida es indicador de riesgo de alteraciones cardiacas en la edad adulta.

Yo no sé si estos comentarios científicos, obviamente sin pretenderlo, habrán logrado apagar un tanto el interés de la présencia literaria del corazón. Esta duda me recuerda, sin embargo, una anécdota que narra la ocasión en que el gran físico teórico Richard Feynman fue acusado por un amigo de que, como científico, al estudiar una flor pasaría por alto su belleza. A lo que Feynman respondió: "La belleza que está aquí para ti, también está a mi alcance. Pero yo veo una belleza más profunda a la que no es tan fácil acceder. Puedo ver las complicadas interacciones de la flor. El color de la flor es rojo. ¿Acaso el hecho de que la planta tenga color significa que evolucionó para atraer a los insectos? Cuestión que añade una pregunta adicional. ¿Pueden los insectos ver el color? ¿Poseen un sentido estético? Y así sucesivamente. No veo que el hecho de estudiar una flor le reste nada de su belleza. Sólo lo añaden. De la misma manera, en sus comentarios sobre el mito de la caverna en Platón ( $L a$ source grecque, 1953), Simone Weil recoge la afirmación: «Si el que ha hecho caer las cadenas ha contado las maravillas del mundo exterior, las plantas, los árboles, el cielo, el Sol, no hay más que permanecer inmóvil, cerrar los ojos, e imaginar que es uno mismo el que sale, que trepa fuera de la caverna $y$ que ve todas estas cosas".

Y es así, con estas ideas, como podemos lograr acercarnos a la poesía que encierra el estudio y la resolución de los misterios de la ciencia, y de los secretos del corazón ahora en este rato, cuando al irse resolviendo van apareciendo otros, inspiradores de poesías más elevadas.

Algo como lo que tuvo que inspirar al gran poeta irlandés William $\mathrm{Bu}$ tler Yeats, en el poema:

Tranquilo, tranquilo, corazón trémulo;

Recuerda la sabiduría de los viejos días:

Aquel que tiembla ante la llama y el diluvio,

$Y$ los vientos que soplan a través de los caminos estrellados,

Deja que los vientos estrellados y la llama y el diluvio

Cubran todo y escóndete, porque él no forma parte

De la multitud solitaria y majestuosa. 
No ha sido fácil, en todo caso, para los poetas estrujar las esencias poéticas de los avances científicos. Lawrence, al contrario, manifestó que este progreso, como el de los nuevos datos de la cosmología, era más bien antipoético. Y, así lo refería: «El conocimiento ha matado al Sol, convirtiéndolo en una bola dégas con manchas...El mundo de la razón y la ciencia...éste es el mundo seco y estéril en el que habita la mente abstracta".

Frente a ello, otros, como William Blake, cantaron a la ciencia con reverencia y asombro, como en esta estrofa:

Ver un mundo en un grano de arena

$Y$ un cielo en una flor silvestre

Sostener el infinito en la palma de tu mano

Y la eternidad en una hora.

Y Keats añadía: "La belleza es verdad, la verdad es belleza; esto es todo / lo que sabéis en la Tierra, y todo lo que necesitáis sabern.

Y el propio Einstein aplicó juicios estéticos a la ciencia: «La cosa más bella que podemos experimentar es lo misterioso. Es el origen de todo el arte y la ciencia auténticos».

Por eso, siguiendo las ideas de Feynman, yo quisiera que a nosotros no nos pasara desapercibida la belleza de la ciencia del corazón, la de su anatomía y la de su función; $y$, a la vez, exaltemos cuanta belleza exista en la creación literaria que tenga al corazón como protagonista, o, simplemente, nos demos cuenta de la belleza del lenguaje cotidiano cuando usamos del corazón para calificar nuestros comportamientos y actitudes. Porque de la voz latina cor vienen los derivados cordial, concordia y misericordia; y a la inversa, discordia, incordiar y descorazonamiento. E, incluso, el corazón mismo puede ser leal, sano, dulce, duro, abierto, ardiente, herido, de bronce, y puede ensancharse, descubrirse, traspasarse, atravesarse, achicarse, partirse, abrirse o volcarse; se puede ser blando, duro, limpio, de buen o todo corazón, y de gran corazón; se puede estar con el corazón en la boca, en la mano o en un puño; se puede tener pelos en el corazón, y, sobre todo, mucho, buen o mal corazón o, incluso, hecho una pasa; y el corazón se levanta, se hiela, se gana, se encoge, se calienta, se roba, se bebe o se parte, y nunca es traidor. Además, el corazón apasionado no quiere ser aconsejado, el buen corazón quebranta mala ventura, la boca habla de la abundancia del corazón, algunos son todo corazón y otros van partiendo corazones; a uno le sale algo del corazón o se le sale el corazón por la boca; a otros el corazón le da saltos en el pecho. También, se hace de tripas corazón, se tiene el corazón en su sitio, se asoma el 
corazón a los labios, se habla con el corazón en la mano, se mete el corazón en un puño y hasta puede no caber el corazón en el pecho.

Formas vulgares de hablar que archivan ese significado tradicional que ha hecho del corazón, como traducción de su implicación fisiológica primordial, la sede de los fenómenos afectivos y la expresión de las mejores cualidades espirituales del hombre. Una de las muchísimas muestras de este significado es la que vamos a ver recogida en uno de los breves cuentos de Karen Brentano -reunidos en Historias de almanaque (1875), versión de Tomás Tuero-:

"Tras una tormentosa y oscura jornada invernal, pasada la medianoche, cuando todos dormían, llamaron a la puerta de Albert Desmon, campesino que vivía a los pies del castillo de Coucy. Al abrir se encontraron con un perro vagabundo que apretaba entre sus mandibulas un despojo sanguinolento. Asustados, cerraron la puerta de un golpe. Al abrirla de nuevo, con mucha cautela, vieron que el perro había desaparecido, pero sobre el umbral habia dejado una extraña carga.

Parece un corazón - dijo Robert -. Y no ha sido arrancado a dentelladas, sino por un diestro cirujano. Encargó al mayor de sus hijos que cogiera un caballo y fuera a avisar a la justicia. Pero antes de que la justicia llegara se presentó en la casa Gabriela de Vergi, la señora del castillo, una anciana que nunca salía de sus aposentos. Apretaba contra el pecho un cofre ricamente labrado. Sin que nadie se atreviera a llevarle la contraria, introdujo alli el corazón, que entretanto habia dejado de sangrar, se habia momificado y despedía un agradable olor a flores secas.

Sabia que cumplirías tu promesa - dijo -. Por fin puedo morir tranquila.

Cuando al día siguiente Albert Desmon, acompañado de los alguaciles, subió a ver a la señora, se encontró con que acababa de fallecer. Sus últimas palabras fueron que la enterraran con el cofre.

Luego supimos - contaba Albert - que en Palestina, hace tres siglos, un caballero cristiano, cuando se supo herido de muerte, pidió que su corazón le fuera enviado a su amada Gabriela, que le esperaba en el castillo de Coucy, para que fuera enterrado junto a ellan.

Y con este significado del corazón del cuento nos topamos a lo largo de todas las épocas y todos los estilos de la literatura.

Antes de nada, digamos que Aristóteles avisaba que la amistad no es otra cosa que una alma que rige dos corazones y un corazón que mora en 


\section{Corazón: Ciencia y Literatura}

dos cuerpos. Y, referido a sus estudios zoológicos, afirmaba Aristóteles que todo animal que tiene el corazón grande, naturalmente es temeroso, $y$ si lo tiene pequeño, más de lo que su cuerpo requiere, es atrevido y desvergonzado.

En la incipiente literatura castellana medieval, el corazón es sede de la valentía y las virtudes de los caballeros. Una canción popular canta: "El corazón tengo triste / y el alma tengo confusa. I Algo me va a suceder.../ Triste corazón ¿̇qué anuncias?». En los Romances viejos se canta: "Esforzad, los mis hermanos, / lidiemos con valentía / mostremos gran corazón / contra aquesta morería". En la General Estoria, Alfonso X alababa con frecuencia a sus gentes, así: "Este moço de grand coraçon sera e omne de grand valentian. El Libro de Aleixandre está lleno de referencias al estilo de: "Omnes son astrosos / de flacos coraçones / non valen pora armas".

En la literatura mística - San Juan de la Cruz, Santa Teresa, Fray Luis de Granada, Fray Luis de León - el corazón esta presente como sede del amor a lo divino. Fray Luis de Granada abunda en la perfección de la vida espiritual a través del amor del corazón. Lo vemos en unas cuantas referencias de su "Guía de pecadores": "Salomón en sus Proverbios dice: descubre tu corazón al Señor y espera en él»; "el contentamiento del corazón humano es dádiva de Dios»; "porque donde está su amor alli está preso su corazón; aunque no se pierda por eso su libre albedrio»; "bastaba la menor parte de este galardón para mover nuestros corazones al amor de la virtud"; "el corazón que pensaba sobre ti pensamientos de paz y de amor, piensa ahora pensamientos de aflicción y dolor»; y "en el tiene su descanso, en el su gloria, en el su esperanza, en el todo su corazón y pensamiento». San Juan de la Cruz lo expresaba así: «El corazón que está llagado con el dolor de tu ausencia, sanará con el deleite y gloria de tu dulce presencia»; "Ni yo miraba cosa, / sin otra luz ni guía / sino la que en el corazón ardía». Y en los Nombres de Cristo, de Fray Luis de León, se lee: "Pues sea esto lo primero, que los justos son dichos ser generosos y liberales, porque son demostraciones y pruebas del corazón liberal y generoso de Dios». El Padre Sigüenza, en la Historia de la Orden de San Jerónimo, aseguraba: "Siente en el corazón tal regocijo, que solo el que lo siente es quien lo entiende...". Es seguramente en Santa Teresa de Jesús, y en el famoso poema que comienza "Vivo sin vivir en mi», donde el corazón aparece como la superación de la transformación espiritual de la materia, inflamada por el amor, cuando escribe: "Esta divina prisión / del amor con que yo vivo, / ha hecho a Dios mi cautivo, / y libre mi corazón; / y causa en mi tal pasión / ver a Dios mi prisionero, / que muero porque no muero". 
Diego Hurtado de Mendoza (1503-1575), en Definición de los celos: "Son celos exhalaciones / que nacen del corazón, / sofística presunción / que pare imaginaciones / de muy pequeña ocasión".

La fase fundacional del nuevo género literario de los libros de caballerías culminó en los comienzos del siglo XVI con el Amadís de Gaula. El más valiente caballero fue, a la vez, el más leal enamorado, y, en los esquemas narrativos de la obra, el corazón aparece con gran frecuencia armando las virtudes del personaje. Veamos algunas de ellas: "Amadís se assentó al pie de un árbol y començó a mirar la villa y vio las torres y los muros assaz altos y dixo en su coraçón: ¡Ay, Dios!, ¿dónde está alli la flor del mundo?»; "Y Amadís le dixo: ¡Cómo eres loco en esto que dices!; sábete que no tengo seso, ni coraçón, ni esfuerço, que todo es perdido quando perdí la merced de mi señora, que della y no de mi me venía todo..."; "Bien puede ser-dixo Amadís-, mas bien sé quel vuestro no se faría de tan buen coraçón como el mío pequeño, según vuestra desmesura y mal talante; y pues me queréys conoçer, sabed que yo soy Amadís de Gaula"; "Señor, del ardimiento de vuestro coraçón no sé nada; pero nunca vi caballero que tan fermoso armado paresciesse»; "Señora, aquel coraçón que tuvistes para errar, aquel tened agora para os dar remedio en tanto vuelvo a vos"; "Quando Garadán oyó fablar de hombre de tan alto fecho de armas, mudósele el coraçón en dos guisas: la una pesarle porque tal caballero fuesse de la parte del rey, y la otra plazerle por se combatir con él»; "Yo vos lo diré -dixo la donzella-. Agora sabed que aquel gran caballero que en la batalla murió, amaba mucho a la donzella que vuestro huésped llevó consigo; mas ella lo desamaba de todo su coraçón, y amaba al que la distes más que todas las cosas del mundon.

Toda la obra de Cervantes está plagada de nuevas expresiones en las que juegan los diferentes atributos del corazón. En boca y actitudes de los personajes del Quijote: "Vamos señor dixo Sancho, que las barbas y lagrimas destas señoras las tengo clavadas en el coraçon...", "...denme a mi que Quiteria quiera de buen coraçon y de buena voluntad a Basilio...", "No llores maesse Pedro, ni te lamentes, que me quiebras el coraçon", "quedó el Maestresala traspasado su coraçon, y propuso de luego otro día pedirsela por muger a su padre....", "...y considera, que se suele dezir, que buen coraçon quebranta mala ventura». Y lo miso ocurre en todas sus novelas y comedias. En El celoso extremeño: "Quando esto oyó Leonora, se arrojó a los pies de su marido, y saltándole el coraçon en el pecho le dixo...". En El vizcaíno fingido: "...y hame dado mucho gusto el ver quan sin melindres ni rodeos me ha descubierto su coraçon...". En Persiles: 
"...ensanchad los coraçones, y no deis lugar que reyne en ellos la melancolía...". En El coloquio de los perros: "...llevaba atravesados en el coraçon sus dos hijos, y nunca quiso, aun en el artículo de la muerte, perdonar a la Camacha...". En La Ilustre fregona: "...y ella y la huespeda se assieron una a otra, y començaron a hazer tan amargo llanto que quebrava los coraçones de quantos la escuchaba". En Galatea: "Y con gran celeridad se iba a pasar el coraçon con ella».

Prácticamente lo mismo podríamos decir en los versos de Lope de Vega. En La ingratitud vengada: "Muera yo en Italia bella, / tierra descansada y ancha, / que el corazón se me ensancha / sólo en pensar que he de vella». En La desdichada Estefanía: "Mal sin regalo os detengo, / aunque en aquesta ocasión, / ya que a recibiros vengo, / he ensanchado el coraçon, / donde como a hijo os tengo". En El castigo sin venganza: "Ya determinada estuve; / pero advertir es razón / que por una mano sube / el veneno al corazón". En El cordobés valeroso: "Tiene razón Pedro en esto; / quien no tiene coraçon / para seguir su opinión, / vuelvese a su casa presto". En La campana de Aragón: "O fiero esquadron villano, I tan malo es un Rey christiano, / santo, humilde e inocente, / piadoso, justo, clemente, / de coraçon limpio y sano?". En La corona merecida: "Que aunque bizarra y vestida / me ve, y tan disimulada, / soy mançana coloreada, / en el corazón podridan. Y del primer cuarteto del soneto de $R i$ mas sacras son los versos: "Si de la muerte rigurosa y fiera / principios son la sequedad y el frío, / mi duro corazón, el hielo mío / indicios eran que temer pudiera». Y en otro de estos sonetos: "jOh duro corazón de mármol frío!, / ¿tiene tu Dios abierto el lado izquierdo, / y no te vuelves un copioso rio?»"

Y parece lógico que en la poesía calderoniana, y de una manera más lírica, no deje de abundar. En Ero y Narciso: "Que inquietamente confusa, I no sé que siento en el alma, / que a golpes dentro del pecho / el corazón se me arranca». En Dicha y desdicha del nombre: "No sé quien al corazón / le enseñó una oculta ciencià, / que la sabe sin saber / como ni cuando se aprende». En El hijo del sol Faeton: "Arrancarte el corazón / quisiera, porque después / de muerta, quedar no pueda / tan grande secreto en él».

En la novela costumbrista del XIX, Pereda abunda en expresiones como las de El sabor de la tierruca: "iCon que me equivoco? ¡Con que tu corazón no es falso? ;Con que no se apartó del mío de la noche a la mañana?»; "¡Ay, Pablo! No me cabía ya más en el corazón...Porque yo le doy esta cruz al más valiente, y a ver cómo la lleva»; "Pues entonces, sobran 
los reparos, Juan, y, si un poco me apuras, toda explicación entre nosotros; porque donde habla el corazón calla la boca»; "De lo que te pasa, a nadie culpes en ley de justicia; que seas valiente, no se te ha negado; pero que, con sólo decirlo, llegues a campar aquí, no lo sueñes nunca. Por el corazón se mide a los hombres y no por la estampa, y corazón no falta al más ruin de los presentes". De Sotileza son asimismo las expresiones: "Empeño de no callarte ni siquiera un pensamiento, para que llegaras a verme el corazón como en la palma de la mano». Y "En cuanto fue latiendo al ordinario compás su corazón honradote, observó que en lo más hondo de él había una espina que le punzaban.

$\mathrm{Y}$, para terminar, unos minutos con algunos de los más famosos poetas del último siglo ¿Quién no recuerda aquella Canción de Otoño en Primavera, de Rubén Darío? Aquella que comienza: «Juventud, divino tesoro, / iya te vas para no volver! / Cuando quiero llorar, no lloro... / y a veces lloro sin querer...". Pues, a continuación, siguen los versos: "Plural ha sido la celeste / historia de mi corazón. / Era una dulce niña, en este / mundo de duelo y aflicción"......."YY las demás! En tantos climas, / en tantas tierras siempre son, / si no pretextos de mis rimas / fantasmas de mi corazón".

Juan Ramón Jimenez tiene un poema titulado Jardines dolientes que no me resisto a leerlo entero:

"Tú me miras llorando

-será el tiempo de las flores-,

tú me mirarás llorando,

y yo te diré: - No llores.

Mi corazón, lentamente, se irá durmiendo...Tu mano

acariciará la frente

sudorosa de tu hermano...

Tú me mirarás sufriendo, yo sólo tendré tu pena;

tú me mirarás sufriendo,

tú, hermana, que eres tan buena.

$Y$ tú me dirás: -¿Qué tienes?

$Y$ yo miraré hacia el suelo.

$Y$ tú me dirás: -¿Qué tienes?

$Y$ yo miraré hacia el cielo. 


\section{Corazón: Ciencia y Literatura}

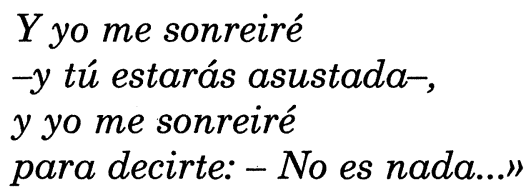

Muchas, muchas veces, en la prosa y la poesía de García Lorca, sobre todo en sus sonetos, anda el corazón por medio. En el soneto Llagas de amor, el último terceto es así: "Y aunque busco la cumbre de prudencia, / me da tu corazón valle tendido / con cicuta y pasión de amarga ciencia». En otro soneto, el titulado El poeta pregunta a su amor, también su último terceto es así: "¿No viste por el aire transparente / una dalia de penas y alegrías / que te mandó mi corazón caliente?». En Noche del amor insomne, hay varios lugares para el corazón. Veámoslo:

"Noche arriba los dos con luna llena, yo me puse a llorar y tú reías.

Tu desdén era un dios, las quejas mías momentos y palomas en cadena.

Noche abajo los dos. Cristal de pena, llorabas tú por hondas lejanías.

Mi dolor era un grupo de agonías sobre tu débil corazón de arena.

La aurora nos unió sobre la cama, las bocas puestas sobre el chorro helado de una sangre sin fin que se derrama.

$Y$ el sol entró por el balcón cerrado y el coral de la vida abrió su rama sobre mi corazón amortajado".

De Rafael Alberti, lo vamos a ver en uno de sus más famosos poemas, el titulado «Se equivocaba»:

"Se equivocó la paloma:

Se equivocaba.

Por ir al Norte, fue al Sur.

Creyó que el trigo era agua.

Se equivocaba.

Creyó que el mar era el cielo;

que la noche, la mañana.

Se equivocaba. 
Que las estrellas, rocío; que el calor la nevada. Se equivocaba.

Que tu falda era tu blusa; que tu corazón, su casa. Se equivocaban.

No podría terminarse esta relación sin la presencia de Antonio Machado que tiene un poema, en el que el corazón es su esencia misma. Se titula Anoche cuando dormía:

"Anoche, cuando dormía, soñé, jbendita ilusión!, que una fontana fluía dentro de mi corazón; di, ¿̇por qué acequia escondida, agua, vienes hasta mí, manantial de nueva vida en donde nunca bebí?

Anoche, cuando dormía, soñé, jbendita ilusión!, que una colmena tenía dentro de mi corazón; y las doradas abejas iban fabricando en él, con las amarguras viejas, blanca cera y dulce miel.

Anoche, cuando dormía, soñé, jbendita ilusión!, que un ardiente sol lucía dentro de mi corazón.

Era ardiente porque daba calores de rojo hogar, y era sol porque alumbraba, y porque hacía llorar.

Anoche, cuando dormía, soñé, jbendita ilusión!, que era Dios lo que tenía dentro de mi corazón". 


\section{Corazón: Ciencia y Literatura}

Un poeta argentino, muerto hace una docena de años, Francisco Luis Bernárdez, tiene un largo, bellísimo poema, titulado Estar enamorado. Tiene la ventaja que pueden tomarse de él, a gusto del consumidor, los versos aislados que uno desee. El primero de ellos dice así: "Estar enamorado, amigos, es encontrar el nombre justo de la vidan. Y, unos cuantos que yo he seleccionado para este rato dicen:

Estar enamorado........

Es ver el mar desde la torre donde ha quedado prisionera nuestra infancia.

Es apoyar los ojos tristes en un paisaje de cigüeñas y campanas.

Es ir leyendo lo que escriben en el espacio las primeras golondrinas.

Es ver la estrella de la tarde por la ventana de una casa campesina.

Es ignorar en qué consiste la diferencia entre la pena y la alegría.

Es escuchar a medianoche la vagabunda confesión de la llovizna.

Es despertarse una mañana con el secreto de las flores y las frutas.

Es comprobar en cuerpo y alma que la tarea de ser hombre es menos dura.

Es empezar a decir siempre y en adelante no volver a decir nunca.

Es divisar en las tinieblas del corazón una pequeña lucecita.

$\mathrm{Y}$, para terminar, un corto poema de Unamuno. Me parece que sus versos son capaces de unir todo lo que yo os he contado en esta tarde de ciencia y literatura del corazón. Dice así, y concluyo:

"El corazón? Aurículas...ventrículos

fascículos...no sé...

los nombres más ridículos...

bajo los nombres, ¿qué?

¡Oh la leyenda! Un músculo

que lanza sangre de que se hace hiel;

mas al tocar la vida su crepúsculo

uno se muere de él». 